Cita: Herrero Ruiz de Loizaga, F. Javier (2006): "El paréntesis etimológico en el DRAE-2001", en Mar Campos Souto e Ignacio Pérez Pascual, eds., El diccionario de la Real Academia Española: ayer y hoy, A Coruña, Universidade da Coruña, Anexos de Revista de Lexicografía, 1, pp. 155-166. https://doi.org/10.17979/spudc.9788497497466.155

\title{
El paréntesis etimológico en el DRAE-2001
}

\author{
F. JAVIER HERRERO RUIZ DE LOIZAGA \\ Universidade Complutense de Madrid \\ Instituto Universitario Menéndez Pidal
}

(cc) BY-NC-SA

La preocupación por la etimología de las palabras ha sido una constante en la tradición lexicográfica española desde Covarrubias a la actualidad, y se halla presente en el quehacer académico desde la elaboración del Diccionario de Autoridades. Aunque desde la edición del Diccionario de la lengua castellana de 1780 la Academia elimina las etimologías, a partir de la duodécima edición, de $1884,{ }^{1}$ adopta el uso de proporcionar las etimologías de (algunas de) las palabras que incluye en su repertorio, y lo sigue manteniendo en las sucesivas ediciones hasta la vigésima segunda y última (2001), ejemplo que ha sido seguido también por otros diccionarios monolingües. El criterio de inclusión de las etimologías es algo conforme al espíritu académico desde la fundación de la Institución (recuérdese la defensa de su estudio para la lexicografía en el «Discurso proemial sobre las etymologías» del Diccionario de Autoridades), y éstas se incluyen de un modo decidido desde 1884, momento en que la investigación etimológica está produciendo importantes frutos. ${ }^{2}$ Dado que no existía en esos momentos un diccionario etimológico riguroso del español, a pesar de algunos intentos en tal sentido en el siglo XIX, la utilidad de estas etimologías es manifiesta; pero con la aparición de los dos grandes diccionarios etimológicos del español a mediados del siglo xx, el de Vicente García de Diego (1954) y el de Corominas (1954-1957 y 19801991) -tenidos muy en cuenta, sobre todo el último, por la propia Academia para la revisión de sus etimologías, especialmente a partir de la edición de 1984- su utilidad

1 Sobre la preocupación etimológica en la tradición lexicográfica española, vid. con más detalle Fajardo Aguirre (1999: 155-157).

2 No mucho antes se había publicado Diez (1858), con sucesivas ediciones revisadas y suplementos en las décadas siguientes. 
ha sido cuestionada por algunos especialistas, entre quienes no faltan los defensores de su eliminación en un diccionario general de carácter sincrónico. ${ }^{3}$ Aunque pensamos que la información etimológica sí puede tener interés, no para el filólogo especialista, pero sí para el lector medio culto, no entraremos en la polémica sobre su conveniencia en un diccionario general; nos limitaremos simplemente a estudiar algunos aspectos del modo en que se ofrecen dichas etimologías. Naturalmente, puesto que el $D R A E$ no es un diccionario etimológico y no está destinado a un público especializado, el espacio destinado a la etimología ha de ser necesariamente limitado, y se reduce generalmente a la mera presentación de las etimologías, sin extenderse en la explicación o discusión de las mismas.

Desde la edición de 1884, la Academia adopta la convención de proporcionar las etimologías de las palabras que incluye en su repertorio dentro de un paréntesis que sitúa detrás del lema y antes de la información gramatical y la definición, convención que sigue manteniéndose en las sucesivas ediciones hasta la vigésima segunda y última (2001), y que ha sido adoptada también por la mayoría de los diccionarios monolingües del español, como el de María Moliner, el Vox o el Diccionario Esencial Santillana de la Lengua Española, convirtiéndose así en la forma más generalizada en la lexicografía española para la indicación de las etimologías. ${ }^{4}$ La información etimológica contenida dentro del paréntesis es autónoma e independiente de la definición que sigue. Sin embargo, excepcionalmente hay alguna remisión de la definición a la etimología, como sucede en el caso de brabante:

brabante. (De Brabant). m. Lienzo fabricado en el territorio de este nombre, en Bélgica y los Países Bajos.

Aunque el diccionario académico ofrece en las «Advertencias para el uso de este diccionario» un pequeño apartado referente a la información etimológica (DRAE2001: XLIV-XLV), lo cierto es que no señala con claridad cuáles son los criterios que ha utilizado en la elaboración y presentación de los materiales, y ésta no se efectúa de un modo absolutamente regular. La forma más frecuente de introducir la etimología consiste en la utilización de la preposición de, indicadora del origen, seguida del nombre del idioma, muchas veces en abreviatura, del que procede el étimo, ya sea el latín en palabras patrimoniales y latinismos, ya sea otro idioma en el caso de préstamos: del

3 Vid. por ejemplo Porto Dapena (2002: 193); vid. un repaso histórico respecto a la consideración de las etimologías en los diccionarios generales en Prat Sabater (2000: 527-530). Drysdale (1989: 526527) señala algunas razones para ofrecer las etimologías de las palabras en los diccionarios generales.

4 Aunque también es frecuente esta colocación en otras tradiciones lexicográficas, en algunas, como la inglesa, es mucho más frecuente que en la española la situación de las etimologías al final del artículo (vid. Drysdale 1989: 528 y Fajardo Aguirre 1999: 157). 
lat., del ár., del fr., del gr., del it., del port., etc., y posteriormente de la forma de la palabra en el idioma de procedencia. En alguna ocasión aparece detrás de la preposición de una palabra sin indicación del idioma de procedencia, cuando se trata de una palabra española. Esto puede ser debido a que haya una alteración formal respecto a una forma anterior. Por ejemplo en «mezcolanza. (De mescolanza)», y tendremos que ir al lema correspondiente a la forma dada en el paréntesis para conocer la etimología lejana: «mescolanza. (Del it. mescolanza)». Si esa forma anterior ya ha desparecido y no tiene entrada en el diccionario, se da la forma de procedencia precedida de la abreviatura ant., y tras la forma antigua su etimología, como en «bizma.

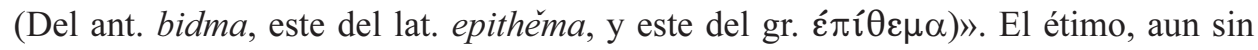
cambiar de forma respecto al lema, puede ir precedido de la categoría gramatical si lo que quiere indicarse es que ha habido históricamente un proceso de metábasis, con abandono posterior de los usos originales: así la etimología del sustantivo marisco es «(Del adj. ant. marisco, del mar)». Con más frecuencia falta la indicación del idioma de procedencia cuando el origen del término está en el propio español, pero no se trata de que haya habido una modificación formal de una forma preexistente, no son tanto casos en que se indique el étimo del que procede un término con las modificaciones formales que en su caso haya podido experimentar, sino que se utiliza para explicar una forma creada en castellano mediante derivación. En estos casos, se da en el paréntesis la base sobre la que se ha dado la derivación, como en «fusilar. (De fusil)», si bien esto no se produce de un modo sistemático, pues, como el propio DRAE-2001 advierte «el paréntesis etimológico no aparece en artículos donde no es útil, generalmente porque la primera acepción nos da la información necesaria para deducir el origen de la voz». Sin embargo, aunque esto es lo que generalmente sucede, no faltan ejemplos en que esa norma se rompe, tanto por el hecho de que se da la etimología a pesar de ser deducible de la primera acepción: «abarrotar. (De barrote). tr. apretar o fortalecer con barrotes algo», como por lo contrario: «pulsera. f. Cerco de metal o de otra materia que se lleva en la muñeca para adorno o para otros fines». ${ }^{5}$ Mucho menos frecuentes son otras formas de introducción de la etimología. En algún caso aparece la preposición por encabezando la información etimológica: «aniejar. (Por añejar)», parece indicar al mismo tiempo la procedencia y que se trata de una deformación de la voz original. «Por alus». se utiliza con mucha frecuencia cuando la etimología propuesta para un apelativo es un nombre propio de persona, especialmente cuando se trata de una persona real o personaje de ficción caracterizados por un determinado rasgo bien conocido: «judas. (Por alus. a Judas Iscariote, por quien Jesús fue vendido a los judíos)», «quijote². (Por alus. a don Quijote de la Mancha)»; pero no es un

5 Vid. sobre la forma de indicar la derivación en la información etimológica Jiménez Ríos (2000), de donde procede el ejemplo de abarrotar. 
procedimiento sistemático: «maritornes. (De Maritornes, personaje del Quijote, de M. de Cervantes, 1547-1616)». No se usa en cambio «por alus». cuando el étimo de un apelativo es un nombre propio de lugar, aunque excepcionalmente aparezca dentro del paréntesis etimológico para completar la información con una referencia específica: «babel. (De Babel, ciudad de Asia, por alus. a su mítica torre)». Otras formas de introducción en las que no aparece una preposición son «Acort.», como en «foto 2 . (Acort.) f. coloq. fotografía», o «Eufem.», como en «ajo. (Eufem. por carajo)». Pero la forma más frecuente de introducir la información etimológica después de la utilización de la preposición de es el uso del término voz, seguido del adjetivo que hace referencia a la lengua de procedencia de dicha voz. Este procedimiento, sin embargo, no resulta del todo claro. Si el lema aparece recogido en letras redondas en el diccionario, hay que suponer que se trata de una voz española, independientemente de cuál sea su origen. En principio cabría entender que las palabras cuya etimología viene expresada de esta manera, sin indicación de forma alguna para el étimo originario, tienen exactamente la misma forma que la del étimo en el idioma de que se trate. Sin embargo esto no parece ser siempre así. Es significativo que en la inmensa mayoría de los casos se recurre a ese tipo de marcación cuando se trata de idiomas por lo general poco conocidos en España: así podemos ver «apacheta. (Voz aim.)», «iglú. (Voz esquimal)», «kéfir. (Voz caucásica)», etc., o voces procedentes de lenguas ya desaparecidas y no documentadas, como las de la España prerromana: con frecuencia de hecho no puede precisarse la lengua concreta y se utiliza la descripción de voz prerromana, como en balsa $^{1}$; mientras que si se trata de palabras procedentes de idiomas bien conocidos se da en el apartado etimológico el étimo exacto, incluso si este coincide en la forma gráfica y básicamente en la pronunciación con la española. Así podemos ver «capo. (Del it. capo, cabeza, aplicado a los jefes de la mafia)» o «airbag. (Del ingl. airbag)». Por el contrario, sólo si la Academia considera que se trata de voces extranjeras aún no plenamente aclimatadas al español, y especialmente cuando presentan «dificultades gráficas o de pronunciación» se utiliza para la etimología la indicación voz, y además el lema aparece en cursiva (a diferencia de casos como apacheta, iglú, etc.): «majorette. (Voz fr.)»; «pizza. (Voz it.)», «byte. (Voz ingl.)», «czarda. (voz húngara)», etc. ${ }^{6}$ Alguna

6 No obstante, la divisoria entre el extranjerismo más o menos aclimatado al español no es completamente nítida. El criterio de la Academia es básicamente ortográfico: cuando no hay correspondencia entre la representación gráfica y la pronunciación en español se utiliza la cursiva y el paréntesis encabezado por voz. De este modo, airbag aparece tratado, como hemos visto, como cualquier palabra del léxico español, en tanto que brandy aparece en cursiva y tratado como voz inglesa, a pesar de ser voz más tradicional e integrada en el vocabulario castellano; whiskey aparece en cursiva y remite a güisqui sin cursiva y con etimología («de or. ingl.»), aunque obviamente la pronunciación es la misma y la forma gráfica preferida claramente la primera. De hecho, whiskería se incluye en el diccionario sin cursiva, por ser un derivado creado en español, a pesar de que la forma gráfica no se corresponda con la pronunciación. 
vez, aunque obviamente es mero despiste, se olvida poner el origen de la voz, como sucede en fondue. Otro recurso que utiliza el diccionario académico cuando no señala con exactitud la forma del étimo es encabezar el paréntesis etimológico con la secuencia «de or.» seguido del nombre del idioma del que procede el étimo, aunque sin precisar su forma, hecho frecuente, aunque no exclusivo - vid. por ejemplo «bonsái (De or. jap.)»- en el caso de voces que proceden de lenguas amerindias: «cacique, ca. (De or. caribe)», «calquín. (De or. pampa)», «canoa. (De or. taíno)». Algunas de estas lenguas amerindias, como el taíno, desaparecieron pronto, por lo que sólo en algunos casos puede precisarse el étimo (como en maíz); por el contrario, en otros casos, siendo lenguas que sobreviven en la actualidad, especialmente en el caso del nahua, suele darse la forma concreta del étimo. ${ }^{7}$ Algunas veces se suman los dos procedimientos y hallamos la secuencia «voz de or.», como en «artiga. (Voz de or. prerromano)», o en el impreciso «chaquira. (Voz de or. americano)». Cuando se trata del latín u otras lenguas europeas bien conocidas, tampoco encontramos este tipo de etimología, sino la remisión al étimo concreto. Resulta por ello sorprendente un paréntesis etimológico como «corpus ${ }^{2}$. (De or. lat.)», cuando la etimología es clara, pues se trata de un latinismo crudo en lo formal, y es la misma que se aplica para corpus $^{1}$. En principio parecería lógico deslindar las dos formas de introducción de etimología, reservando la secuencia «de or.»+ adjetivo que indique procedencia para aquellos casos en que pueda señalarse un origen, pero, al menos por el momento, no pueda precisarse la forma exacta del étimo; y la secuencia «voz» + adjetivo relativo al idioma cuando se trata de un extranjerismo sentido aún como tal.

Un elemento que se presenta con cierta frecuencia dentro del paréntesis etimológico es la abreviatura $c f$. 'cónfer (compárese, véase)'. Aunque no se utiliza para introducir términos que se presenten como étimos, puede introducir una información valiosa al proponer la comparación con una palabra de una lengua o lenguas con la que pueda tener relación: «bardo'. (Del celtolat. bardus; cf. irl. ant. bard y galés bardd)»; y en ese sentido puede servir para dar cierta fuerza a una posible hipótesis. Por ejemplo en «chocolate. (De etim. disc.; cf. nahua xocoatl, de xoco, amargo y atl, agua)», donde la semejanza con la formación nahua parece apuntar a ese origen; pero en algunos casos resulta difícil saber adónde quiere apuntar la información que se nos ofrece con $c f$. Por ejemplo en «carona. (De or. inc.; cf. lat. caro, carnis, carne)», ¿Quiere indicar un posible aunque no bien explicado origen latino, o apuntar

7 Lógicamente no resulta igual de sencillo realizar las etimologías de lenguas bien conocidas que de aquellas de las que los redactores de la obra pueden tener escasas noticias. Habría que contar para ello con el concurso de especialistas. De hecho no faltan algunos trabajos que se refieren a las voces procedentes de una o varias lenguas y su tratamiento en el $D R A E$, que podrían aprovecharse para una mejora de las etimologías, como Lope Blanch (1998-1999) o Hernández (2000). 
hacia la posibilidad de que proceda de una lengua indoeuropea que presente un étimo formalmente semejante al de latín?; «guarismo, ma. (cf. algoritmo)», ¿quiere decir que la etimología es o tal vez sea la misma que la de algoritmo?; en «bacalao. (Del eusk. bakailao; cf. neerl. ant. bakeljauw, var. de kablejauw)» ¿Qué información se nos quiere transmitir a través de la comparación entre el vasco y el holandés antiguo? Aparte del hecho de que la etimología última de la palabra no sea probablemente vasca, sino occitana (parece la etimología más aceptada, dentro de la discusión sobre el origen de este término, aunque efectivamente el vasco pudo ser la lengua transmisora al castellano), y habida cuenta de que no existe relación de pertenencia a una misma familia lingüística entre el vasco y el holandés, ¿quiere indicarse que la voz holandesa es un préstamo vasco; que la voz vasca es un préstamo holandés; que existe una fuente común de la que proceden la forma holandesa y vasca; y en tal caso, por qué no se explicita? ¿Qué importancia tiene para la comprensión de la etimología castellana esta semejanza entre vasco y holandés? En cualquier caso, la indicación $c f$. puede ser de utilidad en algunas etimologías, pero debería evitarse o modificarse la redacción en aquellos casos en que no aclara nada y puede conducir a confusión.

Otro elemento importante en las informaciones etimológicas es la indicación de la lengua de procedencia. Como ya hemos visto, esto se hace frecuentemente mediante la utilización de un adjetivo que se refiere a dicha lengua, muchas veces a través de una abreviatura, especialmente cuando se trata de lenguas que se citan reiteradamente en los paréntesis etimológicos. En principio no hay problemas en estas indicaciones. Cuestión de escasa importancia es si podría resultar más clara, por abarcadora, la utilización de un término como «occitano» en lugar de «prov.» que prefiere la Academia. Quizá uno de los usos más peculiares sea el de celtolatino, adjetivo, que según define la propia Academia, sólo se emplea para referirse a palabras de origen celta incorporadas al latín, término que, como señala Velasco, «parece conveniente porque en la mayor parte de los casos es difícil seguir la pista a la lengua particular que ha servido de vía para la incorporación al latín» (2000: 488). Sin embargo, y aunque el término se usa con frecuencia, no deja de haber casos en los que se dice en primer lugar «del lat. + étimo», y en segundo lugar, «de or. celta», como en bayo. En algún caso se utiliza también el término galolatino, que en principio podría entenderse una especificación del más amplio celtolatino referido a incorporaciones al latín de una lengua céltica concreta, pero a diferencia del término anterior, galolatino, según el $D R A E$, sí se refiere a una variedad lingüística: «Se dice de la variedad de latín caracterizada por elementos lingüísticos galos, que se habló en la Galia»; así, un caso como $\mathrm{braga}^{l}$, que en el $D R A E-1992$ recibía etimología celtolatina, lleva ahora el paréntesis «(Del galolat. braca, quizá de or. germ.)», y puede plantear la duda de si con ello se quiere decir que procede del latín hablado en la Galia, pero en este caso concreto es un probable germanismo, y no voz de origen celta, o - como probablemente es la intención de la etimología- si se trata de un préstamo llegado al latín a 
través del galo, y a este de una lengua germánica. Otra cuestión relativa a los celtismos es que, aunque no han podido llegar directamente al español a través del celtíbero o de otras lenguas celtas continentales, pues no ha habido un período de tiempo en que estas y el castellano convivieran, sino que lo han hecho a través del latín hablado, no siempre se conserva un testimonio escrito del celtismo en época latina, por lo que en estos casos no se recurre al rótulo celtolatino, sino que la etimología que se da es directamente celta, con lo cual puede dar la impresión al lector no avezado en la filología de un paso directo de las lenguas celtas al español: «borona. (Quizá del celta *borŭna)», «huelga ${ }^{2}$. (Del celta hisp. *ǒlga, cf. galo ólca)». ${ }^{8}$ En las voces de origen latino, se hacen a veces precisiones de utilidad, como lat. vulg. o b. lat., aunque éstas no son sistemáticas y pueden faltar: por ejemplo en cizaña se da simplemente la indicación «(Del lat. zizanı̆a [...])», sin mayor precisión, aunque se trata de latín medieval; y hay una cierta diversidad de maneras de referirse a las palabras de origen prerromano que han llegado al español a través del latín. Se utiliza acertadamente lat. hisp. en casos como estepa 'mata resinosa', «(Del lat. hisp. stippa)», pues parece haber sido palabra propia del latín hispánico, ${ }^{9}$ que no deja descendencia más que en lenguas de la península ibérica, frente a casos como arroyo o coscojo, a los que se da etimología latina y se añade después «voz de or. hisp.», pues, aunque su origen está en una lengua hispana prerromana, no fueron voces exclusivas del latín de Hispania. Lo que no queda del todo claro es la diferencia entre «or. hisp.» y «or. prerromano», como se atribuye por ejemplo a «conejo. (del lat. cunicŭlus, de or. prerromano)» o a páramo. Las voces de origen hispánico en latín son obviamente voces procedentes de alguna lengua prerromana que no puede precisarse, y aunque en principio el rótulo «prerromano» es más amplio, pues podría referirse a voces de origen prerromano extrapeninsular, parece reservarse, como vemos en los ejemplos anteriores, para aquellos casos en que es seguro o muy probable el origen hispánico. Algunas precisiones llegan a ser sorprendentes, como la de «cama ${ }^{1}$. (Del lat. de San Isidoro cama, por camba)». Es cierto que el testimonio de esta forma nos llega a través de San Isidoro, pero la palabra misma no procede de San Isidoro, no es invento suyo, lo único que hace es utilizarla. Quizá sería más adecuado utilizar la indicación «del lat. hisp.». Por

8 Dado que los étimos que se proponen en ejemplos como estos van precedidos de un asterisco que indica que son formas hipotéticas no documentadas, y puesto que la forma reconstruida tiene exactamente la forma que del latín hubiera conducido a la palabra española podrían haber sido catalogadas también, con ese mismo asterisco, como celtolatinas. Algo distinto son casos como «brío. (Del celta *brigos, fuerza)».

9 No obstante, el sintagma latín hispánico, de modo semejante a lo que veíamos antes para el galolatino, se refiere a la variedad de latín hablado en la Península Ibérica, que contendría un número superior de voces de lenguas hispánicas prerromanas que el latín de otras áreas, pero no son los únicos hechos léxicos caracterizadores de esta variedad, por lo que el uso de este rótulo puede generar también cierto grado de ambigüedad si lo que queremos es referirnos a la procedencia prerromana de un término. 
otra parte, la referencia a San Isidoro puede hacer pensar al consultor del diccionario que se trata de un término tardío, cuando quizá remonte a una lengua prerromana.

Otro problema al que se enfrentan las etimologías del diccionario es el del estrato al que se remontan. ¿Se da sólo la etimología directa, o hay que ir más atrás en el proceso de transmisión en caso de que esto sea posible? Las soluciones que da el $D R A E$ en este punto son diversas. En algunos casos, como sucede con el léxico español de origen latino, se da lógicamente la etimología latina. Ocasionalmente, la forma española se explica por un étimo básico, modificado en algún aspecto por la acción de una segunda palabra latina, lo que acertadamente se explica a veces, como en «huraño. (Del lat. foraněus, con influencia de hurón)»; aunque en otros casos, como el bien conocido de cerrojo se señala exclusivamente el étimo latino VERUCŬLUM sin mencionar la influencia formal de cerrar. La etimología, obviamente, es la misma en el caso de los pares de palabras patrimonial y culta que constituyen dobletes, y por lo tanto el paréntesis etimológico coincide en casos como delicado y delgado (Del lat. delicātus), aunque a veces la redacción difiere: «cíngulo. (Del lat. cingŭlum, de cingěre, ceñir)», «cincho (Del lat. cingŭlum, ceñidor)». Más sorprendente es el hecho de que para $a l m a^{I}$ se dé la etimología «(Del lat. anı̌ma)», y para ánima «(Del lat. anı̌ma, y este

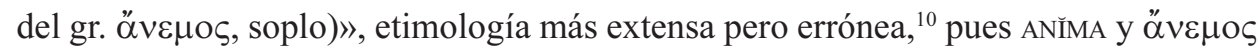
comparten una común raíz indoeuropea *ANE-, pero ninguno de ellos procede del otro. Cuando los étimos latinos proceden a su vez de otra lengua, se añade una segunda etimología que indica de dónde lo tomó el latín. Esto es especialmente frecuente en helenismos adoptados por el latín: «ábaco. (Del lat. abăcus, y este del gr. $\alpha \beta \alpha \xi$ )", y la cadena puede alargarse si la procedencia es aún más lejana «abad. (Del lat. abbas, -ātis, este del gr. $\alpha \beta \beta \beta \alpha$, y este del siriaco $a b b \bar{a}$, padre)». Para indicar las diversas lenguas a las que se va remontando en la cadena etimológica, en el $D R A E-2001$ se va de la más inmediata a la más lejana utilizando de manera generalizada la expresión «este del», como hemos visto en los ejemplos anteriores, abandonando la expresión a través del, que, junto con la anterior, se usaba en el DRAE-1992 con el orden inverso de la cadena lingüística; por ejemplo, para $a b a d$ se daba la etimología con la forma «(Del arameo $a b b a$, padre, a través del gr. $\alpha \beta \beta \alpha$, y del lat. abbas, -ātis)». Para el griego y las modernas lenguas europeas se usa el mismo procedimiento: en general se da el señalamiento de un único étimo del que procede la palabra española. Sólo si la lengua que es inmediata transmisora de la palabra a su vez la recoge de otra que no es su antecesora directa, y por tanto es en ella también un préstamo, se hace constar un origen más remoto. Por ello, en el caso de las lenguas romances, como el italiano, francés, catalán o portugués, la etimología no se remonta al latín. Sí en cambio en el caso de las voces

10 La misma etimología encontramos en Vox y la segunda edición del DUE, probablemente tomadas del DRAE. 
de origen mozárabe, lengua desaparecida y no bien conocida en todos sus aspectos, incluyendo el léxico. Así por ejemplo «alcornoque. (Del mozár. *alqurnúq, y este del b. lat. quernus, encina, var. del lat. quercus, y el suf. hisp. -occus; voz de or. hisp.)». No obstante, como tan frecuentemente sucede en el $D R A E$, no se opera de una manera absolutamente sistemática, y en alguna ocasión, cuando tenemos un préstamo de una lengua romance distinta del mozárabe, también se remonta a la etimología latina, así por ejemplo vemos «terracota. (Del it. terracota, y este del lat. terra cocta)», y esto es especialmente frecuente en el caso del provenzal, para cuyos préstamos unas veces sólo se indica el origen inmediato (balada, capitel, fraile, laurel, mensaje, solaz, etc.), y en otros casos se da también el étimo latino de la voz provenzal (español, prez, monje, remontando en este caso incluso al griego, etc.). Es curioso un caso como «faena. (Del cat. ant. faena, hoy feina, cosa que se ha de hacer)», donde se da correctamente la etimología catalana, pero el significado que se desarrolla es más bien el que corresponde a la palabra latina de la que procede, FACIENDA. En otras ocasiones se da el étimo latino, pero no es el étimo inmediato de la palabra castellana, sino que se salta el intermedio romance, como sucede en «paila. (Del lat. patella, padilla)», pero no viene directamente del latín, sino del francés antiguo paele; y del mismo modo en son se da el étimo latino (sONUs) prescindiendo del intermedio provenzal, o en vinagre sin mencionar el intermedio catalán o provenzal. Cuando alguna lengua romance da un préstamo al castellano, y éste a su vez procede de una lengua distinta del latín, la etimología lejana sí se señala explícitamente, como en «abada. (Del port. abada, y este del malayo badaq)». En el caso de los préstamos ingleses igualmente se explica un segundo paso etimológico cuando el término en el propio inglés es un préstamo, como en «kayak. (Del ingl. kayak y este del esquimal quayaq)», ahora también lógicamente cuando la lengua de procedencia en inglés es el latín: «campus. (Del ingl. campus, y este del lat. campus, llanura)»; aunque también hay casos en los que se da directamente la etimología lejana saltando el intermedio inglés, como en iglú, catalogado como voz esquimal. Un caso especialmente difícil es el que corresponde a un gran número de términos científicos y técnicos, formados con elementos de origen griego y latino. Suelen entenderse como patrimonio cultural conjunto de las lenguas europeas, y generalmente la etimología que se da corresponde directamente al latín y al griego; pero en muchos casos han sido formados previamente en otras lenguas, especialmente francés e inglés, y de ellas han pasado al español. Es, sin embargo, muy difícil precisar todos los casos en que esto ha sucedido. ${ }^{11}$ En las etimologías de origen árabe generalmente se llega a la forma del árabe clásico, con

11 Vid. sobre el problema de la actuación del inglés o francés como puente para la introducción de términos en español Pratt (1992), Lorenzo (1996, esp. 21-24), Gómez Capuz (1997-1998), García Yebra (1999). 
mucha frecuencia señalando la forma del étimo en el árabe hispánico, aunque alguna vez, como en acebuche, se da sólo esta última, y no la forma del árabe clásico. Debido a la existencia generalmente de dos pasos etimológicos - a veces más, cuando a su vez la forma del árabe clásico es préstamo de otra lengua, como azucena, del pelvi; azul, del persa y este del sánscrito; alcázar, del latín-, los paréntesis etimológicos de los étimos de origen árabe, que en el $D R A E$-2001 están a menudo rehechos frente a la edición anterior teniendo en cuenta el Diccionario de arabismos de Corriente (2000), con frecuencia añadiendo la forma del árabe hispánico ausente en la edición de 1992, suelen ser bastante largos. Hay también algunos cambios respecto a la edición anterior en lo que se refiere a la consideración de los mozarabismos. En algún caso se introduce entre el hispanoárabe y el latín el intermedio mozárabe que faltaba, como en «alcaucil. (Del ar. hisp. alqabsíl[a], este del mozár. *kapicéla, y este del dim. del lat. hisp. capřtia, cabeza, por alus. a su forma)», aunque otras veces, se sustituye la etimología mozárabe por la del árabe hispánico, sin que sepamos cuál es la razón, pues Corriente, de quien parece tomarse la cadena etimológica y a veces las explicaciones, mantiene la procedencia mozárabe (romandalusí), como sucede en alcayata o gazpacho.

Por último, y muy rápidamente, quiero referirme al problema del mayor o menor grado de certeza en las etimologías. Como es bien sabido, algunas etimologías son bien conocidas y seguras, pero en otros casos existen dudas, determinadas dificultades en su explicación, y muchas veces hay diferentes propuestas etimológicas. Lógicamente, en el breve espacio dedicado a la etimología en un diccionario general no puede ni debe entrarse en discusiones etimológicas. Las soluciones que adopta la Academia en los casos de etimologías discutidas son variadas. En general, la Academia no presenta distintas propuestas etimológicas; muchas veces toma partido por alguna de las etimologías propuestas sin hacer referencia a otras posibles. Por ejemplo, para braña se da la etimología VORĀGO, -ĬNIS, 'abismo', propuesta por García de Diego, sin ningún matiz de duda, aunque existen otras propuestas, como la de VERĀNEA (Meyer-Lübke 1935), o la de un posible origen prerromano, probablemente céltico (*brakna) que señala Corominas; o para jilguero se ofrece, también sin vacilación, la procedencia de la forma más antigua silguero, y -si buscamos ahora en esta entrada-

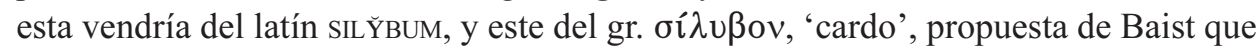
recoge Meyer-Lübke; a pesar de la propuesta etimológica que le hace proceder de sirguero, derivado de SIRGo 'paño de seda', que propuso Menéndez Pidal y retoma Corominas; entre numerosísimos casos que podrían citarse de este tipo. En otras ocasiones, cuando la etimología no es conocida, el $D R A E$ opta por no dar ninguna indicación, se da la ausencia del paréntesis etimológico, como en rácano (la ausencia de paréntesis etimológico puede indicar en consecuencia tanto el desconocimiento de la etimología como, ya lo vimos, que la procedencia de la palabra por derivación es deducible de la primera acepción), pero en otras ocasiones opta por el paréntesis («De 
or. desc.»), como en bayal ${ }^{2}$ o en becerro. En otros casos se aplica el paréntesis («De or. inc.»), como en tomar, que no está claro si quiere indicar un menor grado de incertidumbre, es decir, si ese origen incierto es debido a que todavía no se ha dilucidado cuál es la más probable entre distintas propuestas; pero en ese caso vendría a coincidir con la indicación («De etim. disc.»), como en gaznate o gazuza, con la variante sin preposición («Etim. disc.»), como en bache ${ }^{l}$. En otras etimologías, aunque sigue mostrándose cierta reserva respecto a la seguridad de la procedencia, se hace, sin total certeza, una propuesta. Ya hemos visto que a veces la indicación $c f$. tras de or. inc., aunque no siempre fácil de interpretar, puede apuntar hacia una determinada procedencia, por ejemplo en «armatoste. (De or. inc.; cf. cat. ant. armatost)»; pero más frecuentemente esta indicación se hace a través del empleo del adverbio quizá, como «sacar. (Quizá del gót. sakan, pleitear)», de uso intenso en el DRAE-2001, donde se convierte en indicador por excelencia de una procedencia dudosa, eliminando otras indicaciones como acaso o probablemente que aparecían en la edición de 1992. En alguna ocasión se suman dos indicaciones de duda, lo que parece redundante como en «barranco. (De or. inc., quizá prerromano)», aunque pueda servir para intensificar lo dudoso de la etimología.

En definitiva, creemos que las indicaciones etimológicas del $D R A E$ pueden resultar interesantes para la curiosidad del lector culto medio no especializado, y es claro que a lo largo de las distintas ediciones del diccionario ha habido un proceso de revisión y actualización con la consulta de nuevos materiales. Sería no obstante deseable una revisión minuciosa que -en la medida de lo posible, dado lo ingente de la tarea y teniendo siempre presente lo reducido de esta información en un diccionario general-subsanara descuidos en las mismas y regularizara en mayor grado su presentación.

\section{REFERENCIAS BIBLIOGRÁFICAS}

Corominas, J. (1954-1957): Diccionario crítico etimológico de la lengua castellana, Madrid, Gredos.

Corominas, J. y José A. Pascual (1980-1991): Diccionario crítico etimológico castellano e hispánico, Madrid, Gredos.

Corriente, F. (2003): Diccionario de arabismos y voces afines en iberorromance, Madrid, Gredos.

DIEZ, Friedrich (1858): Etymologisches Wörterbuch der romanischen Sprachen, Bonn, Marcus.

DRAE-2001. Real Academia Española (200122): Diccionario de la lengua española, Madrid, EspasaCalpe. 
Drysdale, Patrick D. (1989): «Etymological Information in the General Monolingual Dictionary», en Franz Josef Hausmann, Oskar Reichmann, Herbert Ernst Wiegand y Ladislav Zgusta, eds., Wörterbücher. Ein internationales Handbuch zur Lexicographie, Berlin-New York, Walter de Gruyter, I, pp. 525-530.

Fajardo Aguirre, Alejandro (1999): «Etimología y lexicografía. Problemas metodológicos», en M. Aleza Izquierdo, ed., Estudios de historia de la lengua española en América y España, Valencia, Universitat de València, Departamento de Filología Española, pp. 155-161.

García de Diego, Vicente (s.a. 1954): Diccionario etimológico español e hispánico, Madrid, SAETA, Madrid; Espasa-Calpe [2 ${ }^{\mathrm{a}}$ ed. aumentada, 1985].

García Yebra, Valentín (1999): Diccionario de galicismos prosódicos y morfológicos, Madrid, Gredos.

Gómez CAPUZ, Juan (1997-1998): «La marcación etimológica de los préstamos (exotismos y cultismos transmitidos por el inglés) en la lexicografía española», Revista de Lexicografía, IV, pp. 91-106.

HERNÁNDEZ, Esther (2000): «Propuestas etimológicas para palabras de origen indoamericano (DRAE,

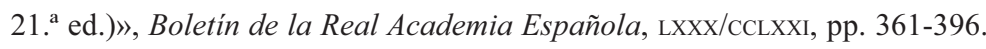

JiMÉNEZ Ríos, Enrique (2000): «Etimología, derivación y definición en los diccionarios del español», en Cuestiones de actualidad en lengua española, Salamanca, Universidad de Salamanca-Instituto Caro y Cuervo, pp. 277-285.

Lope Blanch, Juan M. (1998-1999): «Los nahuatlismos del Diccionario académico», Boletín de Filología, XXXVII, pp. 669-680.

LoREnzo, Emilio (1996): Anglicismos hispánicos, Madrid, Gredos.

MeYer-LÜвKe, W. (1935): Romanisches etymologisches Wörterbuch, Heidelberg, Carl Winters Universitätsbuchhandlung.

Porto Dapena, José-Alvaro (2002): Manual de lexicografía, Madrid, Arco/Libros.

Prat Sabater, Marta (2000): «La información etimológica en el Diccionario de la Real Academia Española (1992)», en S. Ruhstaller y J. Prado Aragonés, eds., Tendencias en la investigación lexicográfica del español. El diccionario como objeto de Estudio. Actas del Congreso celebrado en la Universidad de Huelva, Huelva, Universidad de Huelva, pp. 527-537.

Pratt, Chris (1992): «The status of Loan-words in modern monolingual dictionaries», en Actas del IV Congreso de «Euralex» (Benalmádena 1990), Barcelona, VOX-Biblograf, pp. 509-516.

Velasco López, Ma del Henar (2000): «Consideraciones sobre las etimologías célticas del D.R.A.E.», en A. Bernabé, J. A. Berenguer, M. Cantarero y J. C. de Torres, eds., Presente y futuro de la lingüística en España. Actas del II Congreso de la Sociedad Española de Lingüística, Madrid, Infoprint, pp. 484-493. 